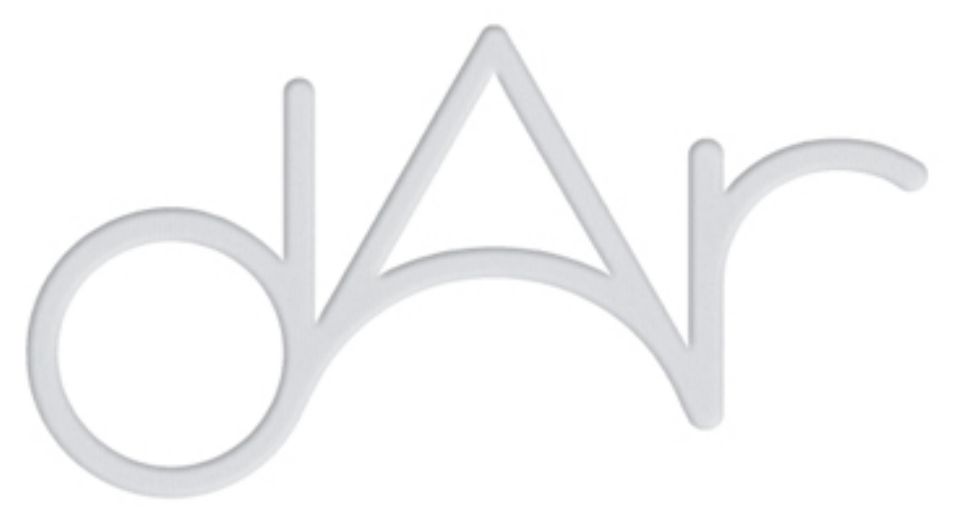

Levantamento e Caracterização do Parque Edificado em Adobe na Cidade de Aveiro

Autor(es): $\quad$ Silveira, Dora; Varum, Humberto; Costa, Aníbal; Lima, Emília

Publicado por: CEAUCP

URL

persistente: URI:http://hdl.handle.net/10316.2/9137

Accessed : $\quad$ 26-Apr-2023 12:49:33

A navegação consulta e descarregamento dos títulos inseridos nas Bibliotecas Digitais UC Digitalis, UC Pombalina e UC Impactum, pressupõem a aceitação plena e sem reservas dos Termos e Condições de Uso destas Bibliotecas Digitais, disponíveis em https://digitalis.uc.pt/pt-pt/termos.

Conforme exposto nos referidos Termos e Condições de Uso, o descarregamento de títulos de acesso restrito requer uma licença válida de autorização devendo o utilizador aceder ao(s) documento(s) a partir de um endereço de IP da instituição detentora da supramencionada licença.

Ao utilizador é apenas permitido o descarregamento para uso pessoal, pelo que o emprego do(s) título(s) descarregado(s) para outro fim, designadamente comercial, carece de autorização do respetivo autor ou editor da obra.

Na medida em que todas as obras da UC Digitalis se encontram protegidas pelo Código do Direito de Autor e Direitos Conexos e demais legislação aplicável, toda a cópia, parcial ou total, deste documento, nos casos em que é legalmente admitida, deverá conter ou fazer-se acompanhar por este aviso.

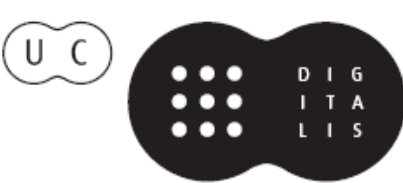


$6^{\circ}$ Seminário de Arquitectura em Terra em Portugal ( $6^{\circ}$ ATP) $9^{\circ}$ Seminário Ibero-americano de Construção e Arquitectura com Terra (9 SIACOT)

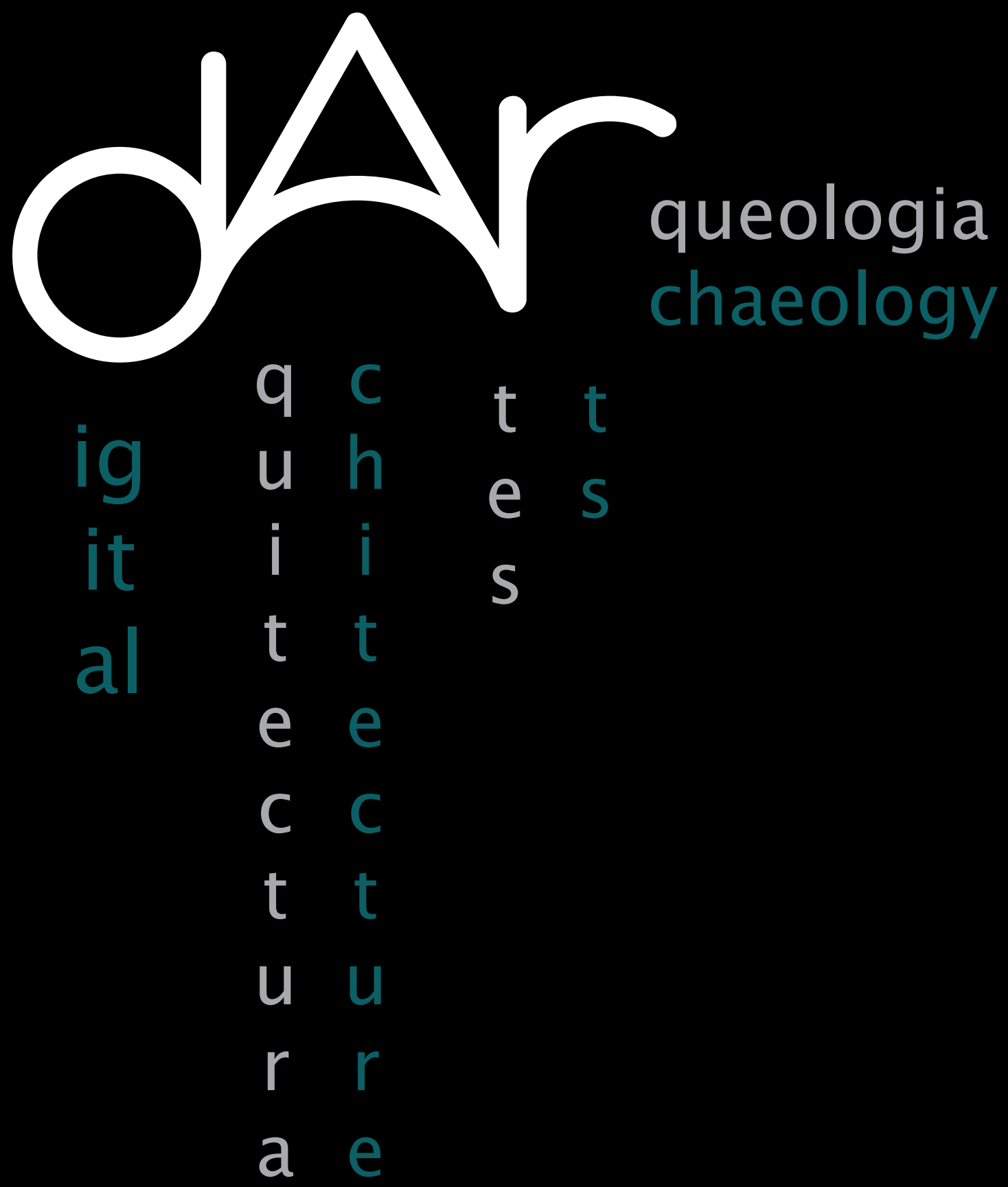




\section{LEVANTAMENTO E CARACTERIZAÇÃO DO PARQUE EDIFICADO EM ADOBE NA CIDADE DE AVEIRO}

Dora Silveira* (Portugal)

Departamento de Engenharia Civil - Universidade de Aveiro

Humberto Varum** (Portugal)

Departamento de Engenharia Civil - Universidade de Aveiro

Aníbal Costa*** (Portugal)

Departamento de Engenharia Civil - Universidade de Aveiro

Emília Lima**** (Portugal)

Câmara Municipal de Aveiro

\section{RESUMO}

Até meados do século XX, o adobe foi um material de construção muito utilizado no distrito de Aveiro, em Portugal. Actualmente, nesta região, e em particular na cidade de Aveiro, permanecem ainda muitos exemplos de edifícios construídos em adobe, alguns de importante valor patrimonial e arquitectónico. No entanto, muitos destes edifícios têm sido votados ao abandono nas últimas décadas, especialmente pela escassez de conhecimento técnico para suporte à sua reabilitação e reforço. Reconhecendo-se esta necessidade de conhecimento, nos últimos anos começou a desenvolver-se trabalho de investigação nesse sentido.

Neste artigo apresenta-se um trabalho de levantamento desenvolvido com o objectivo de caracterizar a distribuição e as características principais da edificação em adobe existente na cidade de Aveiro. Descreve-se, de forma sucinta, a metodologia adoptada, bem como os resultados obtidos. $\bigcirc$ conhecimento adquirido permitirá uma posterior selecção de edifícios representativos, para uma caracterização detalhada dos sistemas construtivos e das patologias mais comuns.

Palavras-chave: Construção de adobe, Aveiro, caracterização.

*dora.silveira@ua.pt

**hvarum@ua.pt

***agc@ua.pt

****melima@cm-aveiro.pt 


\section{INTRODUÇÃO}

Durante largos anos o adobe foi um material de construção muito comum em grande parte do distrito de Aveiro. Por volta de meados do século XX o uso deste material foi sendo gradualmente substituído pelo uso de betão armado e tijolo cerâmico, até ter sido completamente extinguido. Actualmente, o adobe pode ainda ser encontrado com abundância em edifícios rurais e urbanos, alguns de notável valor patrimonial e arquitectónico, como os de estilo Arte Nova na cidade de Aveiro. Segundo estimativa de técnicos da Câmara Municipal de Aveiro, cerca de $25 \%$ dos edifícios existentes na cidade de Aveiro são de adobe, subindo esta percentagem para $40 \%$ no distrito inteiro. A reabilitação e o reforço destes edifícios têm, no entanto, sido negligenciados nas últimas décadas. Como resultado, uma parte significativa apresenta degradação estrutural e não estrutural importante. $O$ processo de reabilitação e reforço apresenta dificuldades relevantes, essencialmente devido à escassez de conhecimento relativo às características e comportamento dos edifícios em adobe.

Com base no reconhecimento da importância da preservação desta herança cultural e arquitectónica, tem-se vindo a desenvolver trabalho para a caracterização dos edifícios em adobe existentes no distrito (Costa et al., 2007; Silveira et al., 2007; Varum et al., 2006; Varum et al., 2008). Em particular, tem-se desenvolvido na Universidade de Aveiro, em colaboração com a Câmara Municipal, um projecto visando caracterizar a distribuição e as características principais da edificação em adobe na cidade de Aveiro. Este conhecimento permitirá a escolha fundamentada de edifícios representativos, para uma posterior caracterização mais detalhada dos sistemas construtivos, bem como das patologias estruturais e não estruturais mais comuns.

Apresenta-se, de seguida, a metodologia e os primeiros resultados do trabalho de levantamento exaustivo realizado nas freguesias da Vera Cruz e da Glória, que constituem a cidade de Aveiro. A freguesia da Glória, apesar de se estender um pouco além dos limites da cidade, foi considerada na sua totalidade.

\section{METODOLOGIA DE LEVANTAMENTO}

O objectivo do levantamento consistiu na identificação e registo dos edifícios em adobe existentes nas freguesias da Vera Cruz e da Glória, tendo sido realizado desde Junho a Setembro de 2009.

A metodologia adoptada passou pelo preenchimento de fichas como a apresentada na Figura 1, complementado com o registo fotográfico do edifício (fotografia da fachada principal e de eventuais pormenores importantes). $\bigcirc$ levantamento pretendeu-se expedito e, por isso, os registos basearam-se na observação rápida, mas atenta, de cada edifício, realizada a partir do exterior (rua de acesso). Para uma mais fácil abordagem, a zona de estudo foi dividida em várias subzonas, como a que se pode observar na ficha exemplo apresentada.

Os parâmetros registados no levantamento são:

(a) ' $N$ ' - Número identificativo atribuído ao edifício (código interno);

(b) 'Conservação' - Estado de conservação do edifício, avaliado com uma classificação de 0 a 5: 0 (ruína), 1 (mau), 2, 3 (razoável), 4 e 5 (bom);

(c) 'Nº de pisos' - Número de pisos do edifício (inclui, sempre que existam, a semi-cave e as águas-furtadas aproveitadas do edifício);

(d) 'Função actual' - Função actual do edifício;

(e) 'Implantação' - Implantação do edifício (que pode ser isolado, em banda meio, em banda extremo, ou em gaveto);

(f) 'Denominação' - Eventual denominação do edifício, sempre que indicada no seu exterior; 
(g) 'No (Pol.)' - Número de polícia do edifício;

(h) 'Ano' - Ano de construção do edifício, sempre que indicado no seu exterior:

(i) 'Obs.' - Eventuais observações consideradas importantes, como por exemplo, relativas à ocupação do dúvida no levantamento. Nesta primeira apresentação de resultados desconsiderouse os edifícios com maior grau de dúvida associado, nomeadamente todas as capelas e igrejas. Depois de terminada a referida investigação, os dados do levantamento assumirão a sua forma final.

De seguida apresentam-se, sucintamente, os resultados principais obtidos. Com este
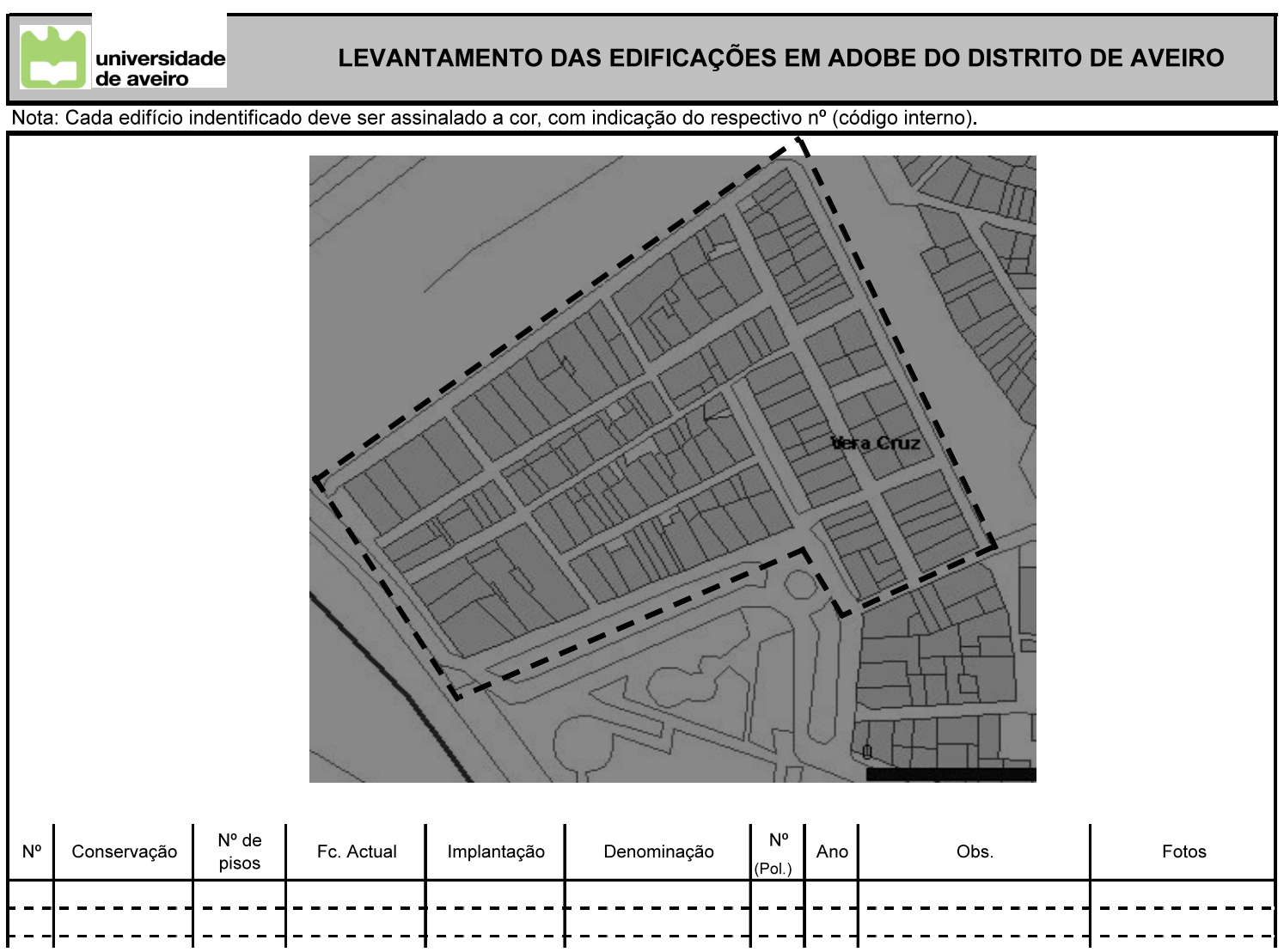

Fig. 1. Exemplo de cabeçalho de ficha de levantamento (Créditos: Dora Silveira, 2009).

edifício;

(j) 'Fotos' - Referência numérica das fotografias tiradas ao edifício.

\section{APRESENTAÇÃO DOS RESULTADOS OBTIDOS}

Após o levantamento geral, está actualmente a ser desenvolvida uma tarefa de investigação na qual se pretende confirmar a existência de adobe em alguns dos edifícios observados que, pelas suas características, suscitaram alguma trabalho pretende-se dar uma imagem global do edificado em adobe nas freguesias analisadas.

\subsection{Informação geral}

Foram registados 780 edifícios em adobe na freguesia da Vera Cruz e 550 na freguesia da Glória, perfazendo um total de 1330 edifícios. São edifícios, na sua maioria, construídos no final do século XIX e na primeira metade do século XX. Grande parte dos edifícios observados possui uma geometria simples, com planta rectangular 
e configuração regular em altura.

\subsection{Parâmetros observados}

Apresenta-se, na Figura 2, o número de edifícios observados por: (a) estado de maior parte dos edifícios (cerca de $80 \%$ ) são constituídos por 1 ou 2 pisos.

Para cada estado de ocupação, verificamse as seguintes percentagens globais:

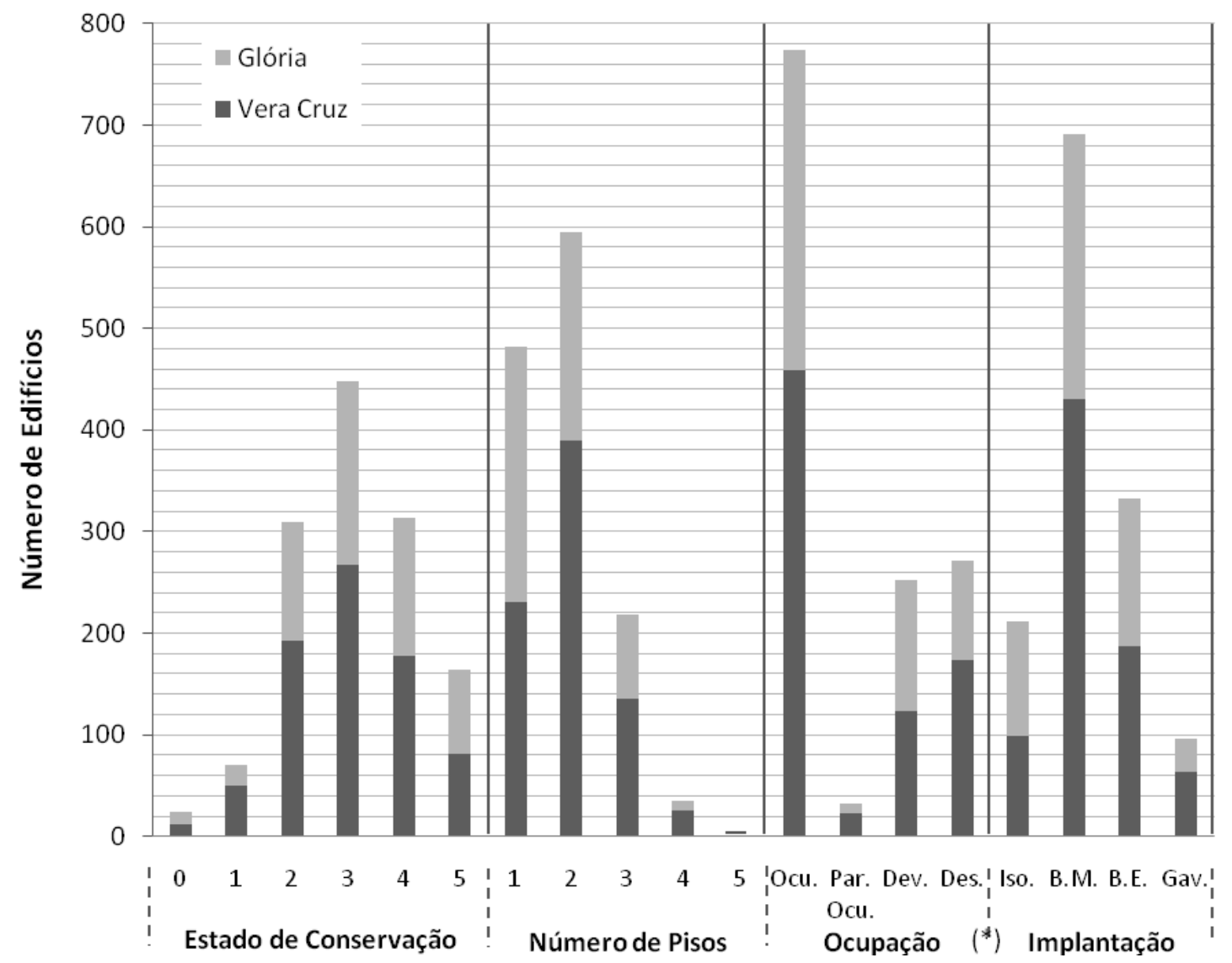

$\left.{ }^{*}\right)$ Ocu. - Ocupado; Par. Ocu. - Parcialmente Ocupado; Dev. - Devoluto; Des. - Ocupação Desconhecida; Iso. - Isolado; B.M. - Banda Meio; B.E. - Banda Extremo; Gav. - Gaveto.

Fig. 2. Número de edifícios observados por: (a) estado de conservação; (b) número de pisos; (c) ocupação; e (d) implantação (Créditos: Dora Silveira, 2009).

conservação; (b) número de pisos; (c) ocupação; e (d) implantação.

Para cada classe de conservação, verificam-se as seguintes percentagens globais de edifícios: 1,8\% (classe 0); $5,3 \%$ (classe 1); $23,3 \%$ (classe 2); 33,7\% (classe 3); 23,5\% (classe 4); e 12,3\% (classe 5). Portanto, cerca de $70 \%$ dos edifícios apresentam um estado de conservação avaliado como razoável (classe 3) ou melhor (classes 4 e 5).

Para cada $n^{\circ}$ de pisos, verificam-se as seguintes percentagens globais de edifícios: $36,2 \%$ ( 1 piso); $44,7 \%$ (2 pisos); $16,4 \%$ (3 pisos); $2,6 \%$ (4 pisos); e 0, $1 \%$ (5 pisos). Portanto, a
$58,2 \%$ de edifícios ocupados; $2,4 \%$ de edifícios parcialmente ocupados; $18,9 \%$ de edifícios devolutos; e 20,5\% de edifícios com ocupação desconhecida.

Para cada implantação, verificam-se as seguintes percentagens globais: $15,9 \%$ de edifícios isolados; $52,0 \%$ de edifícios em banda meio; $25,0 \%$ de edifícios em banda extremo; e 7,2\% de edifícios em gaveto.

Apresenta-se, na Figura 3, o número de edifícios observados, por função. 


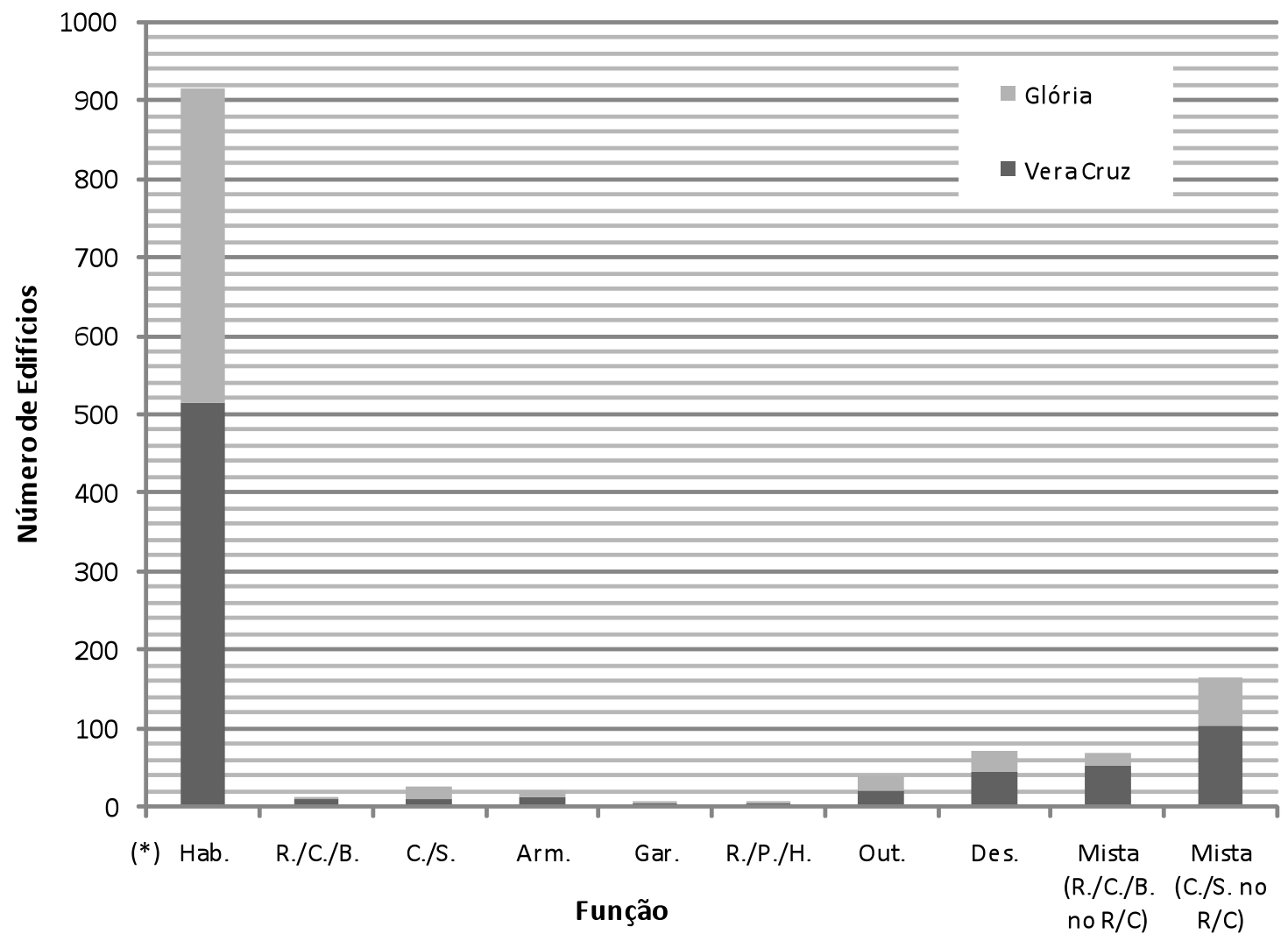

R./P./H. - Residencial / Pensão / Hotel; Out. - Outra função; Des. - Função desconhecida

Fig. 3. Número de edifícios observados por função (Créditos: Dora Silveira, 2009).

Verificam-se as seguintes percentagens globais para as funções mais comuns: $68,8 \%$ de habitações; $12,5 \%$ de edifícios com comércio ou serviços no rés-dochão e outras funções nos restantes pisos (geralmente habitação); 5, $1 \%$ de edifícios com restaurante, café ou bar no rés-dochão e outras funções nos restantes pisos (geralmente habitação).

Apresenta-se na Figura 4, a título de exemplo, três edifícios representativos observados, com indicação dos principais parâmetros associados registados. 

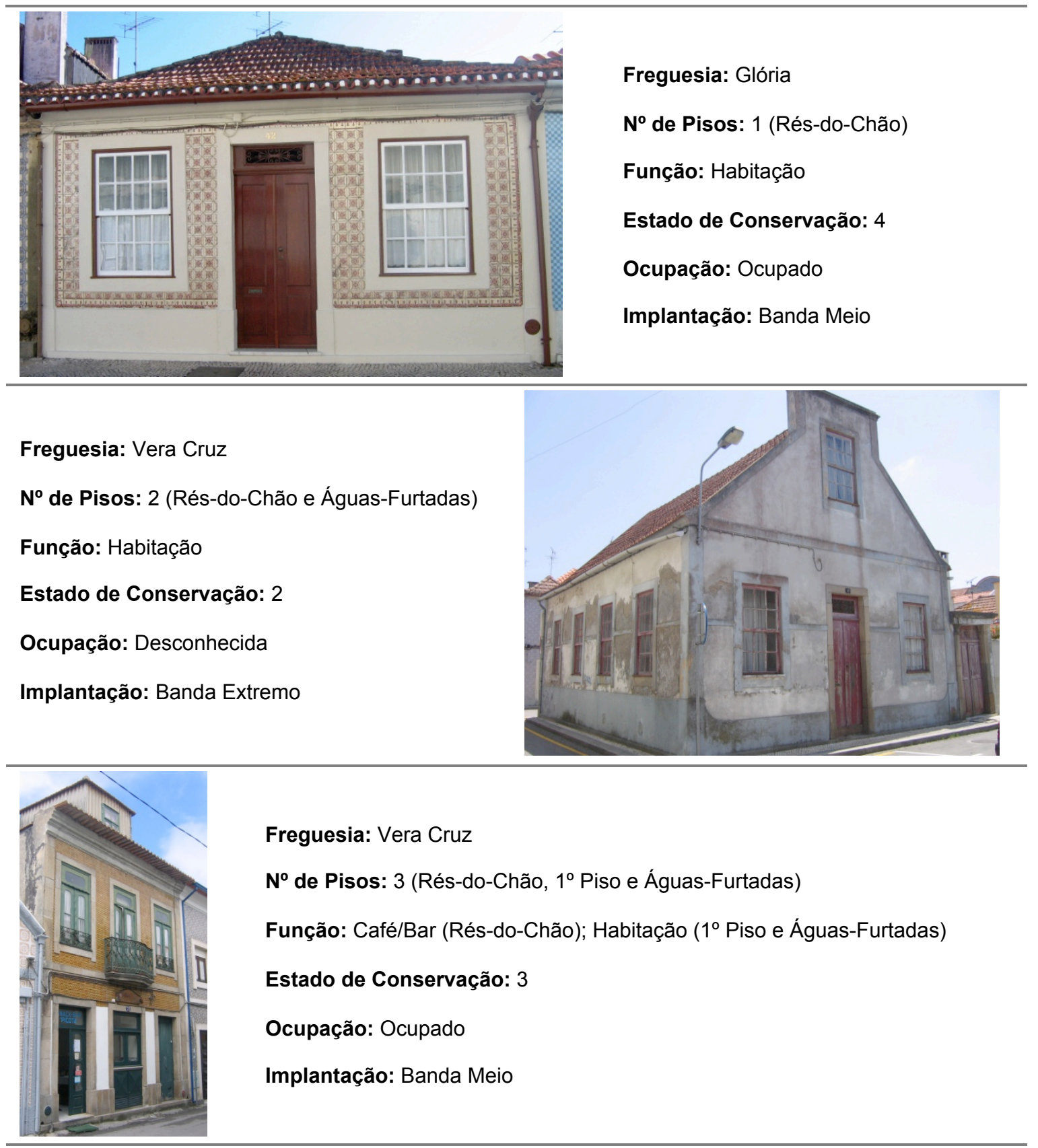

Fig. 4. Exemplos de edifícios de adobe observados (Créditos: Dora Silveira, 2009).

\section{CONCLUSÕES E COMENTÁRIOS FINAIS}

Foi observado um número muito significativo de edifícios em adobe nas duas freguesias em estudo. O facto de se verificar que pelo menos cerca de $60 \%$ dos mesmos se encontram presentemente ocupados, funcionando na sua maioria como habitação, alerta para a necessidade de se desenvolver uma base de conhecimento que possa suportar futuras acções de reabilitação e reforço destes edifícios.

Verifica-se ainda que cerca de $70 \%$ dos edifícios apresentam um estado de conservação considerado 'razoável' ou melhor (classes 3, 4 e 5), e que apenas cerca de $7 \%$ apresentam um estado de conservação avaliado como 'ruína' ou 'mau' (classes 0 e 1). Estes valores sugerem que grande parte dos edifícios existentes, se adequadamente reabilitados e reforçados, 
poderão satisfazer exigências de segurança e conforto compatíveis com aquelas impostas às construções novas.

Os resultados apresentados confirmam a grande expressão do parque edificado em adobe nas freguesias da Vera Cruz e da Glória e, portanto, a necessidade dum esforço no sentido de se conhecer melhor as características e o comportamento destes edifícios. Como foi referido anteriormente, estes resultados servirão de base para a escolha fundamentada de edifícios representativos, para uma posterior caracterização mais detalhada, em termos de materiais, técnicas e estado de conservação.

\section{Bibliografia}

Costa, A., Varum, H., Pereira, H., Rodrigues, H., Vicente, R., Arêde, A., Costa, A.A. (2007). Avaliação experimental do comportamento fora do plano de paredes de alvenaria de adobe. $V$ Seminário Arquitectura de Terra em Portugal, ISBN 978-989-20-09032, Departamento de Engenharia Civil, Universidade de Aveiro, Aveiro, 10 a 13 de Outubro de 2007.

Silveira, D., Varum, H., Costa, A. (2007). Rehabilitation of an important cultural and architectural heritage: the traditional adobe constructions in Aveiro district. In A. Kungolas, C.A. Brebbia, E. Beriatos (Eds) Sustainable Development 2007, pp. 705-714, WITPress: Carvoeiro, Algarve, 25 a 27 de Abril de 2007.

Varum, H., Costa, A., Velosa, A., Martins, T., Pereira, H., Almeida, J. (2006). Caracterização mecânica e patológica das construções em adobe no distrito de Aveiro como suporte em intervenções de reabilitação. Projecto Culture 2000/Mediterrae - Houses and cities built with earth: conservation, significance and urban quality. ARGUMENTUM, 41-45.

Varum, H., Costa, A., Pereira, H., Almeida, J., Rodrigues, H. (2008). Caracterização do comportamento estrutural de paredes de alvenaria de adobe. Mecânica Experimental, vol. 15. APAET: Associação Portuguesa de Análise Experimental de Tensões, 23-32.

Nota

Este artigo refere investigação realizada com o apoio de uma bolsa de doutoramento da "FCT - Fundação para a Ciência e Tecnologia", Portugal. 